\title{
Estágios imaturos de Actinote surima (Schaus) (Lepidoptera, Nymphalidae, Acraeinae) ${ }^{1}$
}

\author{
Márlon Paluch ${ }^{2,3}$ \\ Mirna M. Casagrande 2,4 \\ Olaf H.H. Mielke ${ }^{2,4}$
}

\begin{abstract}
Immature stages of Actinote surima (Schaus) (Lepidoptera, Nymphalidae, Acraeinae). Data on the life cycle and morphology of immature stages of Actinote surima (Schaus, 1902) are presented. The larva feed on leaves of Eupatorium intermedium DC and Eupatorium casarettoi (Rob.) Steyermark (Asteraceae).

KEY WORDS. immature stages, biology, morphology, hostplant
\end{abstract}

Entre os gêneros de Acraeinae somente Actinote Hübner, [1816] possui espécies que ocorrem desde o México até a Argentina, sendo as espécies dos demais gêneros exóticas.

A variação intraespecifica no padrão de coloração das asas (PENZ \& FRANCINI 1996), associada ao número de espécies que ocorrem na região neotropical, sugere uma necessidade de conhecimentos sobre os imaturos, objetivando a correta identificação das espécies. Algumas espécies de Actinote são comuns e abundantes em Curitiba e arredores, Paraná, Brasil, sendo possível encontrá-las voando entre outubro e meados de março.

\section{MATERIAL E MÉTODOS}

Os exemplares de Actinote surima Schaus, 1902 utilizados para este estudo são provenientes de Curitiba e arredores, $900-950 \mathrm{~m}$; Rebouças, $815 \mathrm{~m}$ e região litorânea em Pontal do Paraná, todas localidades situadas no Estado do Paraná, Brasil.

Ovos e larvas foram mantidos em placas de Petri e gaiolas juntamente com folhas e ramos da planta hospedeira. As pupas e os adultos foram mantidos em casa de vegetação.

Exemplares de todas as fases do desenvolvimento foram fixados em líquido Dietrich e os adultos preparados em alfinetes e depositados na Coleção de Entomologia Pe. Jesus Santiago Moure, Departamento de Zoologia, Setor de Ciências Biológicas, Universidade Federal do Paraná, Curitiba, Paraná, Brasil.

Das plantas utilizadas para as posturas e posterior alimentação das larvas, foram preparadas excicatas, identificadas e depositadas na coleção acima citada.

1) Contribuição número 1149 do Departamento de Zoologia, Universidade Federal do Paraná.

2) Departamento de Zoologia, Universidade Federal do Paraná. Caixa Postal 19020, 81531-990 Curitiba, Paraná, Brasil.

3) Bolsista Iniciação Científica, CNPq.

4) Pesquisador $\mathrm{CNPq}$. 
A interpretação da quetotaxia da larva de primeiro instar segue HINTON (1946) e STEHR (1987) e as áreas do corpo conforme PETERSON (1962).

\section{Plantas hospedeiras, oviposição, ciclos e danos}

PENZ \& FRANCINI (1996) listam Eupatorium intermedium DC, Senecio brasiliensis, Mikania hirsutissima, Symphiopappus reticulatus, Eupatorium buniifolium, Symphiopappus casarettoi e para ser estudada a possibilidade de Amaranthus hybridus como citado por BIEZANKO et al. (1974).

As posturas encontradas no litoral, estavam sobre folhas de Eupatorium casarettoi (Rob.) Steyermark, abundante nas restingas, onde foram mantidas durante todo o desenvolvimento larval até o empupamento. Em Rebouças, Curitiba e arredores, as posturas foram encontradas e as larvas alimentadas com Eupatorium intermedium. Dados sobre a duração dos diferentes estágios estão na tabela I.

Tabela I. Actinote surima, duração média dos diferentes ínstares.

\begin{tabular}{lcc}
\hline & Inicio da fase & Duração (dias) \\
\hline Postura & $11 . X I .1997$ & 15 \\
Primeiro instar & $26 . X I .1997$ & 23 \\
Segundo instar & $19 . X I I .1997$ & 21 \\
Terceiro instar & 09.1 .1998 & 24 \\
Quarto instar & $02 . I I .1998$ & 22 \\
Quinto instar & $24 . I I .1998$ & 23 \\
\hline
\end{tabular}

Nos locais estudados A. surima apresentou ciclo bivoltino, com início em outubro/novembro e março/abril. As posturas são feitas na face abaxial da folha em grupos de 200 a 400 ovos, postos lado a lado.

As larvas utilizam o cório como primeira alimentação e aproximadamente vinte e quatro horas após a eclosão, a planta hospedeira, quando praticamente todas as larvas de uma mesma postura já eclodiram. Possuem hábitos gregários até atingirem o tamanho aproximado de dois centímetros, que ocorre ao final do quarto instar. No quinto instar alimentam-se isoladamente nas folhas dos arbustos (Figs 1, 2).

Quando um conjunto de larvas de terceiro ou quarto instar está se alimentando e por algum motivo uma delas é perturbada, tanto a perturbada como as do seu entorno, se enrolam sobre o próprio corpo e se desprendem do arbusto em queda livre. Caso atinjam o solo, tornam a subir pelo caule do mesmo arbusto ou em outro mais próximo, razão pela qual, não é raro encontrarmos uma planta com várias larvas, oriundas de diferentes posturas.

Até o terceiro ou quarto instares, as larvas alimentam-se apenas do parênquima das folhas, deixando as nervuras, posteriormente estas também são utilizadas.

Durante o inverno, em uma das áreas estudadas (Rebouças), após a chegada das geadas severas, a planta hospedeira, pode secar totalmente por estar isolada e desprotegida da mata densa. Eupatorium intermedium é um arbusto típico de áreas com grande incidência de luminosidade solar, abundante em clareiras e beiras de capões às margens da Floresta de Araucária. Este fato pode levar larvas, geralmente 

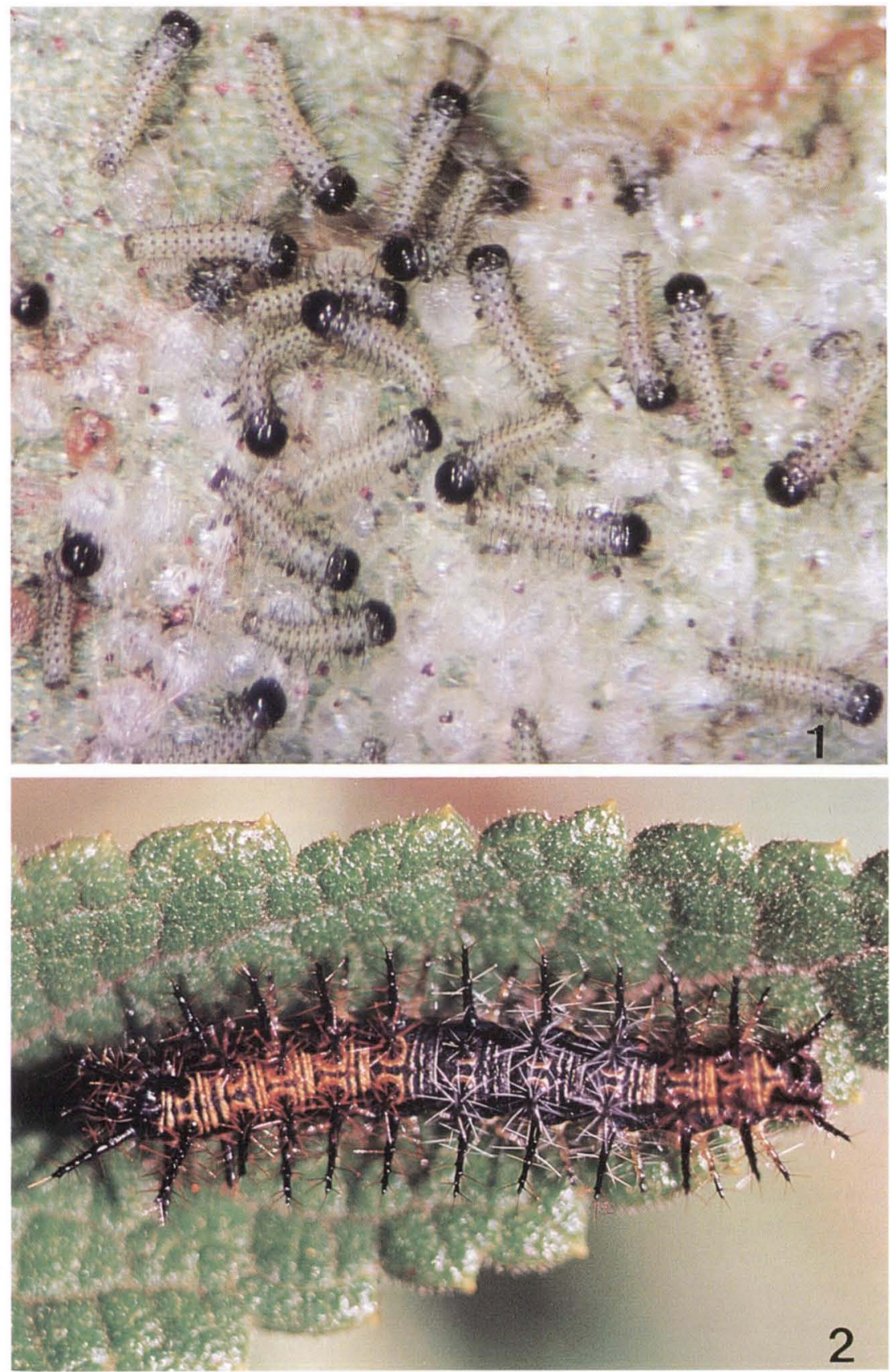

Figs 1-2. Actinote surima, larvas: (1) primeiro ínstar, algumas horas após a eclosão; (2) quinto instar. 
de segundo instar, à morte por falta de alimento. Quando, ao contrário, as larvas encontram nova planta, mantêm o comportamento observado durante o ciclo de verão, isto é, protegem-se na face abaxial da folha. Mesmo em condições extremas, quando a face adaxial é coberta pelo gelo, as larvas mantêm-se na face abaxial e somente após às onze horas da manhã, com a temperatura mais elevada e o gelo derretido, as larvas voltam a se alimentar da planta.

Raramente as larvas empupam na planta hospedeira. Em observações feitas no campo pode-se acompanhar larvas de quinto instar, aproximadamente com três centímetros, que chegam a percorrer uma distância de 15 metros ou mais em busca de local apropriado para empupar.

\section{Morfologia externa dos imaturos}

\section{Ovo (Figs 3-4)}

Em forma de barril, com textura irregular. Área micropilar lisa que, em contraste com o reticulado do restante do cório fornece a impressão, quando observada em vista dorsal, ser deprimida, porém encontra-se no mesmo plano, como também citado por PENZ \& FRANCINI (1996).

Logo após a oviposição a coloração é amarelo-leitosa passando nos dias subsequentes ao róseo intenso. Quando próximo à eclosão, pela transparência do cório pode-se observar a larva de coloração clara, com cabeça escura.

\section{Larva de primeiro ínstar}

Cabeça arredondada, de textura lisa e sem escolos. Coloração geral castanho-escura, com cerdas castanho-claras. As cerdas longas e táteis (HINTON 1946; STEHR 1987), localizadas na face anterior da cabeça são facilmente identificáveis pelas fotos em microscopia eletrônica (Figs 5-7). Cerdas A1, A2 e A3 eqüidistantes e de mesmo tamanho, porém pouco menores que P1 e P2. AF1 e AF2 do mesmo tamanho. $\mathrm{C} 1$ e $\mathrm{C} 2$ têm a metade em tamanho do padrão A1, A2 e A3. L1 é a mais longa e mais afastada de todas. S1, S2 e S3 tão longas como C1 e C2. SS2 exatamente entre os estematas cinco e seis (Fig. 9). SS1 e SS3, pequenas e somente visualizadas em vista ventral (Fig. 7). No labro, três pares de Medianas (M1, M2 e M3) e três de Laterais (La1, La2 e La3), as Medianas pouco menores que as Laterais (Fig. 8). Entre o par de cerdas F1, na região ventral da fronte, encontra-se o ponto Fa. Sobre o quarto estemata está o ponto $\mathrm{Sb}$. Área na base das maxilas revestida com estruturas salientes e de aspecto arredondado (Figs 6-8, 10).

Corpo cilíndrico, branco-leitoso, que após as sucessivas alimentações tornase esverdeado. Sem escolos, apenas cerdas simples de coloração escura. Todas as cerdas partem de placa esclerotinizada, no mesmo plano do tegumento, exceto a cerda SV1 no A10. T1 diferenciado pela presença da placa pronotal, L2 e SV3; ausentes em T2 e T3. Em nenhum segmento torácico ou abdominal encontra-se L3 ou cerdas do Grupo Ventral. Também ausente a cerda SD2 nos segmentos abdominais A1 até A9, aparecendo somente em T2, T3 e na placa suranal. SV1, SV2 e SV3 presente em T1 e A10, neste na placa posterior da coxa; SV1 e SV2 em T2, T3 e SV1 em A2, A7-A9. Ausência de cerdas do grupo Subventral em A1, A3-A6 (Figs 11-13). 

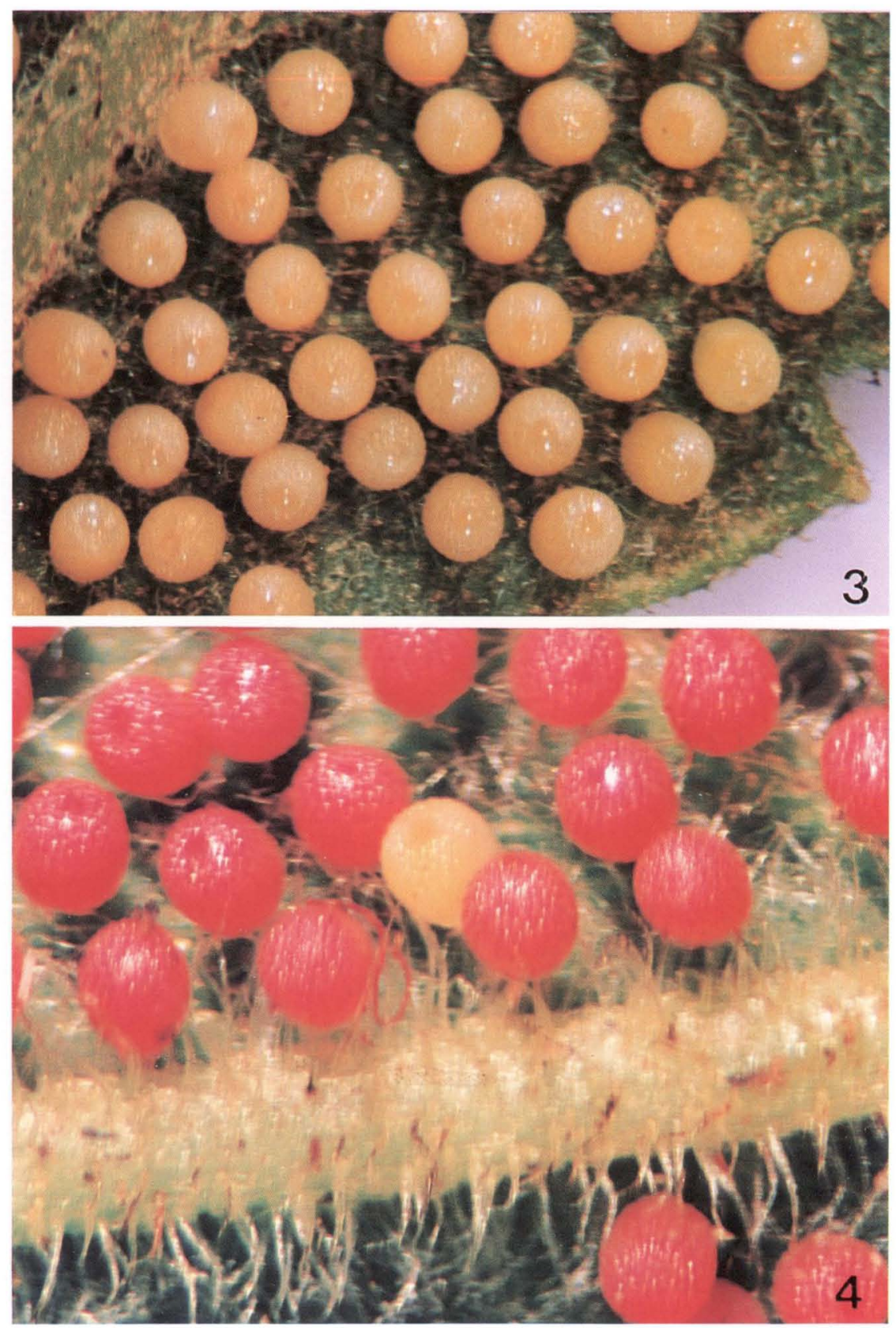

Figs 3-4. Actinote surima, postura: (3) logo após a oviposição; (3) três dias após a oviposição. 

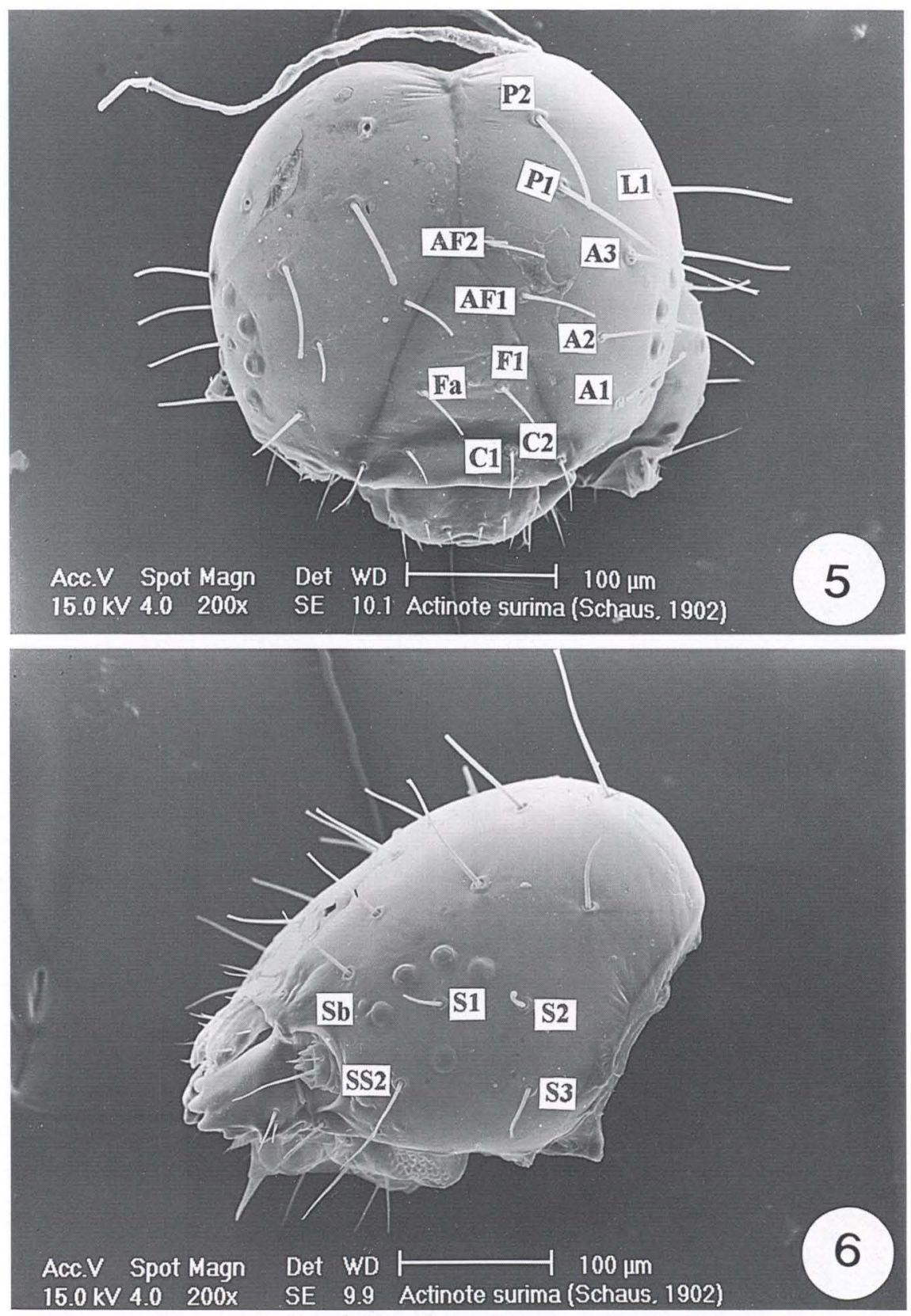

Figs 5-6. Actinote surima, larva de primeiro instar, quetotaxia da cabeça: (5) vista frontal; (6) vista lateral. 

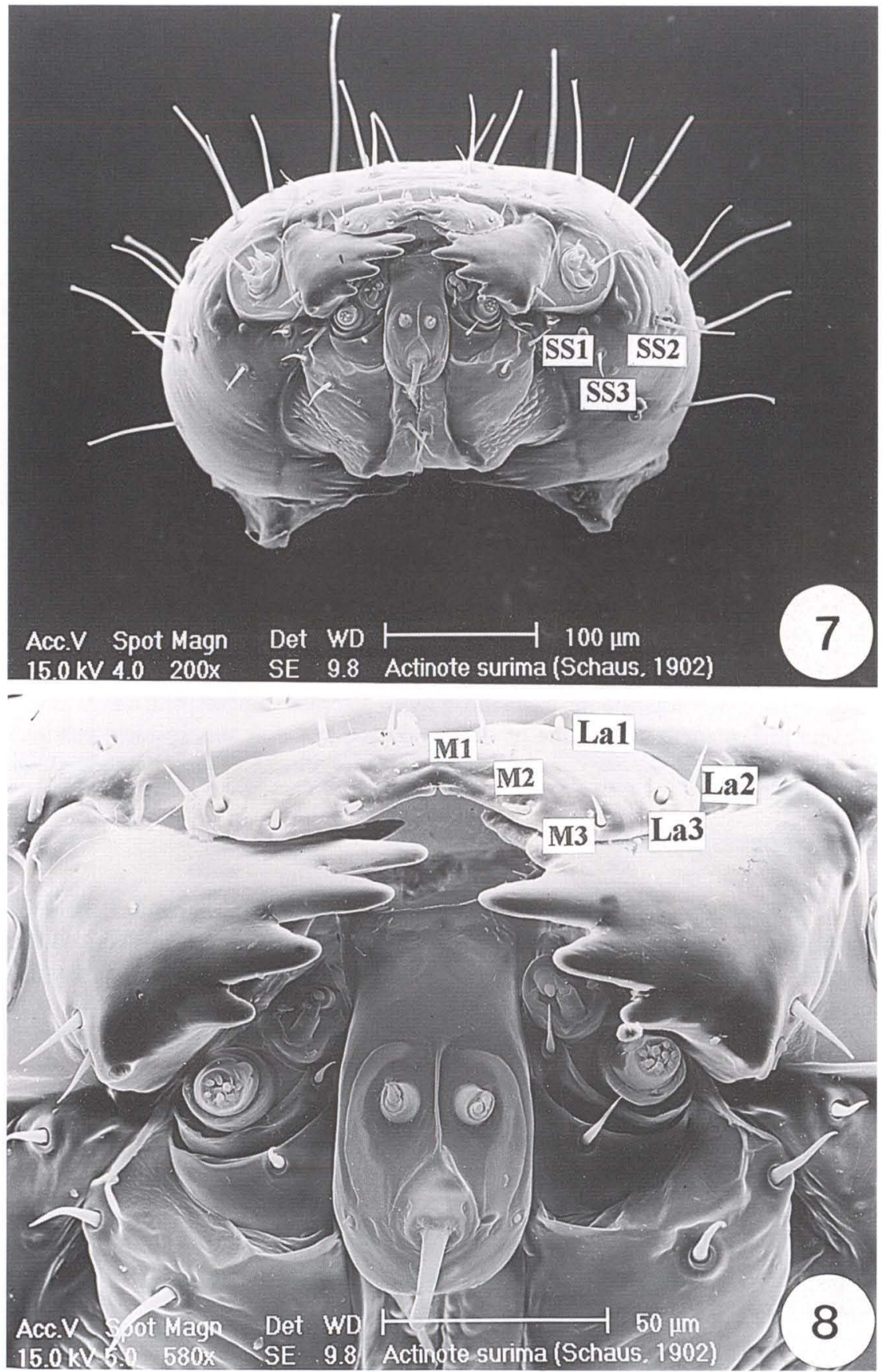

Figs 7-8. Actinote surima, larva de primeiro instar, quetotaxia da cabeça: (7) vista ventral; (8) vista ventral com detalhes do labro, mandíbulas e fiandeira. 


\section{Larva de segundo ínstar}

Cabeça com mesmo aspecto do ínstar anterior, com maior número de cerdas, todas de coloração castanha.

Corpo de coloração amarelo claro, com faixa castanha na área supraespiracular. Escolos dorsais dispostos em linha, ausente em A10. Os torácicos são castanhos com a base e a projeção amarelo-creme, enquanto que os abdominais da mesma cor do restante do corpo. Uma segunda linha de escolos também amareloclaros, menores em tamanho que os dorsais, está presente na área supraespiracular, desde A1 até A10, ausente em A9. Em A10 a coloração do escolo, em algumas larvas, pode ser castanha; neste caso todo o segmento apresenta a mesma cor. Escolos presentes em T2 e T3, na mesma linha que o espiráculo protorácico. Abaixo dos espiráculos e caudal em relação a estes, estão os escolos subespiraculares, presentes de A1-A8. Os escolos dorsais, supraespiraculares e subespiraculares possuem cerdas mais claras que o escolo e não possuem ramificações. Em T1 a T3 onde os escolos estão ausentes, são observadas placas esclerotinizadas castanho escuro, com cerdas claras.

\section{Larva de terceiro ínstar}

Cabeça com mesmo padrão e coloração que o ínstar anterior.

Corpo: escolos torácicos dorsais castanhos, com cerdas claras; abdominais com a metade basal castanho-escura e a metade distal amarelo-clara, exceto em A9, onde o escolo é totalmente castanho-escuro. Escolos supraespiraculares com a mesma padronagem de cor que os dorsais do abdome e os subespiraculares totalmente amarelo-claros, com cerdas castanho-claras. Placas pronotal e suranal bem marcadas.

\section{Larva de quarto ínstar}

Cabeça com mesmo padrão e coloração do ínstar anterior.

Corpo com duas cores distintas; áreas dorsal e supraespiracular, incluindo os escolos, de coloração castanha, escolos com cerdas mais claras. Base dos escolos dorsais castanho-clara até a amarela, formando desenhos de aspecto quadrangular. Espiráculos castanho-escuros a pretos e logo abaixo destes, a coloração do tegumento, incluindo os escolos subespiraculares e toda a área ventral, de coloração escura.

\section{Larva de quinto ínstar}

Cabeça com mesmo padrão de coloração dos ínstares anteriores, exceto pela sutura epicranial que tem coloração branco amarelada.

Corpo como no ínstar anterior, com áreas dorsal e supraespiracular castanho escuro e amarelo, porém mais intenso; formando desenhos quadrangulares mais nítidos. Nos segmentos torácicos a cor castanho-escuro forma algumas linhas que chegam às pernas protorácicas. Nos segmentos torácicos, A1-A3 e A7-A10, escolos de coloração castanho escuro com cerdas castanho-claro. Em A4-A6, as cerdas são hialinas e o amarelo intenso do tegumento dos outros segmentos passa a um branco acinzentado (Fig. 2). Escolos subespiraculares com ápice em castanho-escuro e base com a mesma cor do tegumento. 

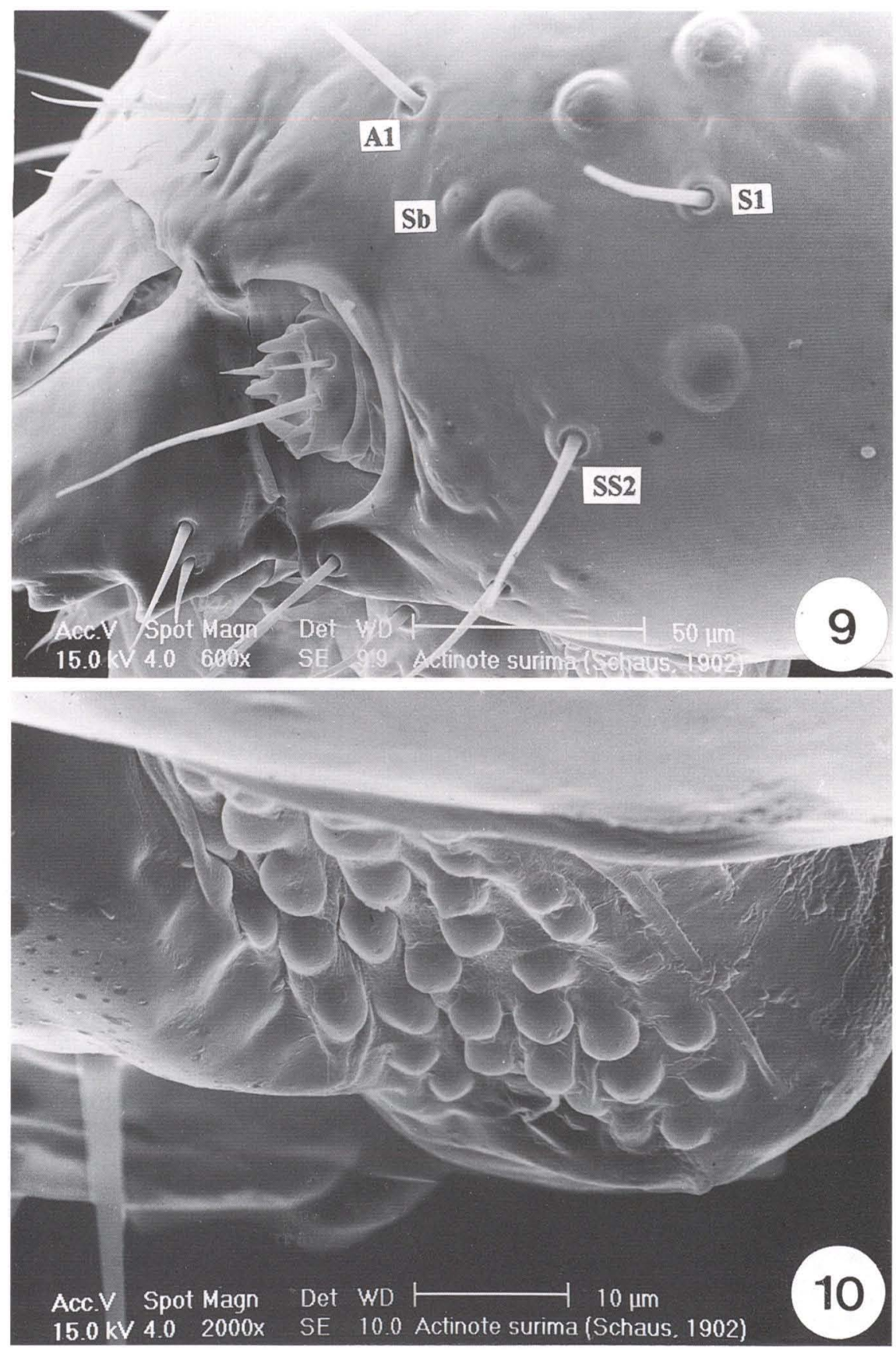

Figs 9-10. Actinote surima, larva de primeiro ínstar, cabeça: (9) vista lateral do conjunto de estematas; (10) vista inferior da base das maxilas. 

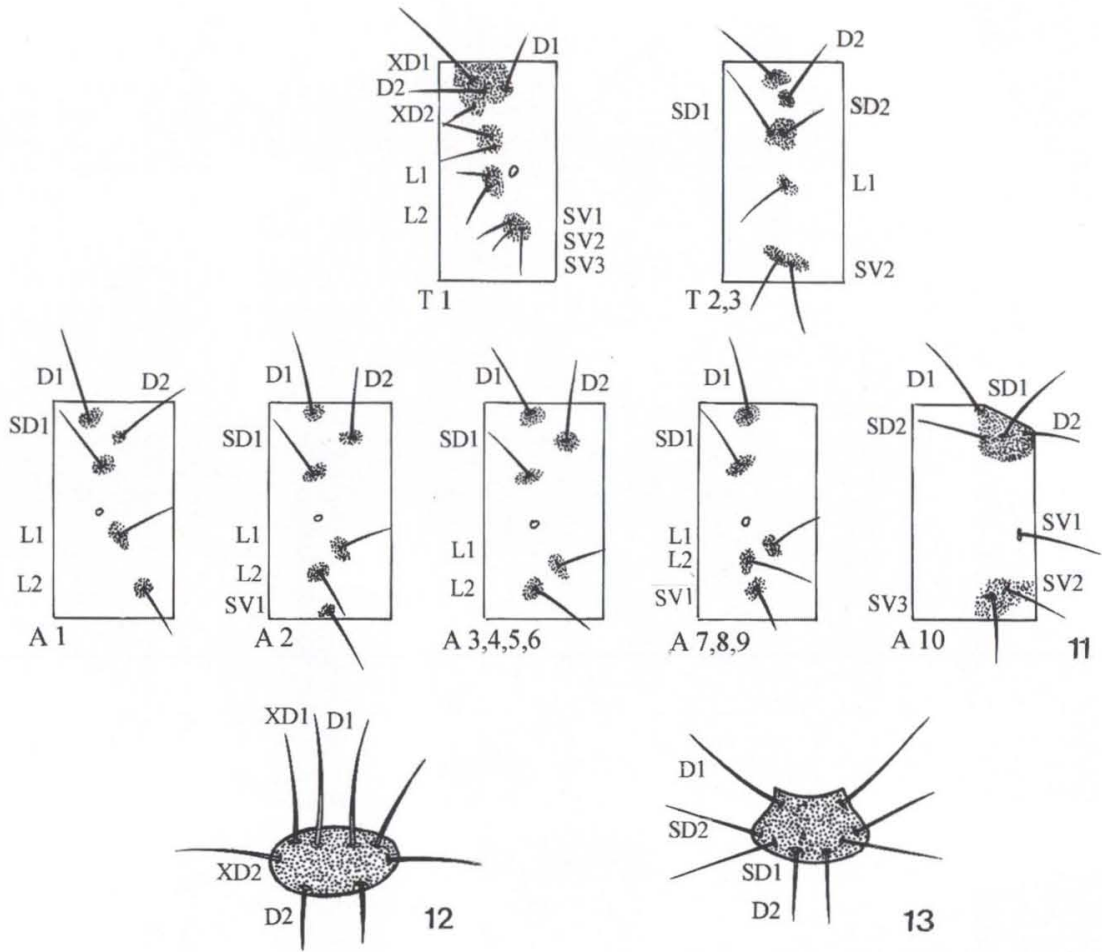

Figs 11-13. Actinote surima, larva de primeiro ínstar, quetotaxia do corpo: (11) segmentos do tórax e abdome; (12) placa pronotal; (13) placa suranal.

\section{Pupa}

Branco amarelada com faixas, ventral, lateral e dorso lateral castanho-escuras. Todo o tegumento é revestido por minúsculas cerdas, imperceptíveis a olho nu, de coloração pouco mais escura que o mesmo. As estruturas da cabeça e do tórax apresentam contorno em castanho-escuro e portanto facilmente reconhecíveis. Pro, meso e metanoto marcados por elevações simétricas, formando três pares que decrescem de tamanho em direção ao metanoto, com a mesma cor branco amarelado do restante do tegumento. De A2 até A6, seguindo a mesma linha de distribuição das saliências no tórax, são encontrados cinco pares de espinhos, em posição látero-dorsal, castanho-escuros, sem ramificações ou cerdas. Estes espinhos estão na mesma faixa castanha-escura dorso-lateral. Região ventral de A9 e dorsal e ventral de A10, totalmente modificadas em uma estrutura de aspecto corrugado, escura com as mesmas cerdas do restante do corpo, formando o cremaster (Figs 14-16). A eclosão dos adultos (Figs 17, 18) ocorreu quinze dias após o empupamento. 

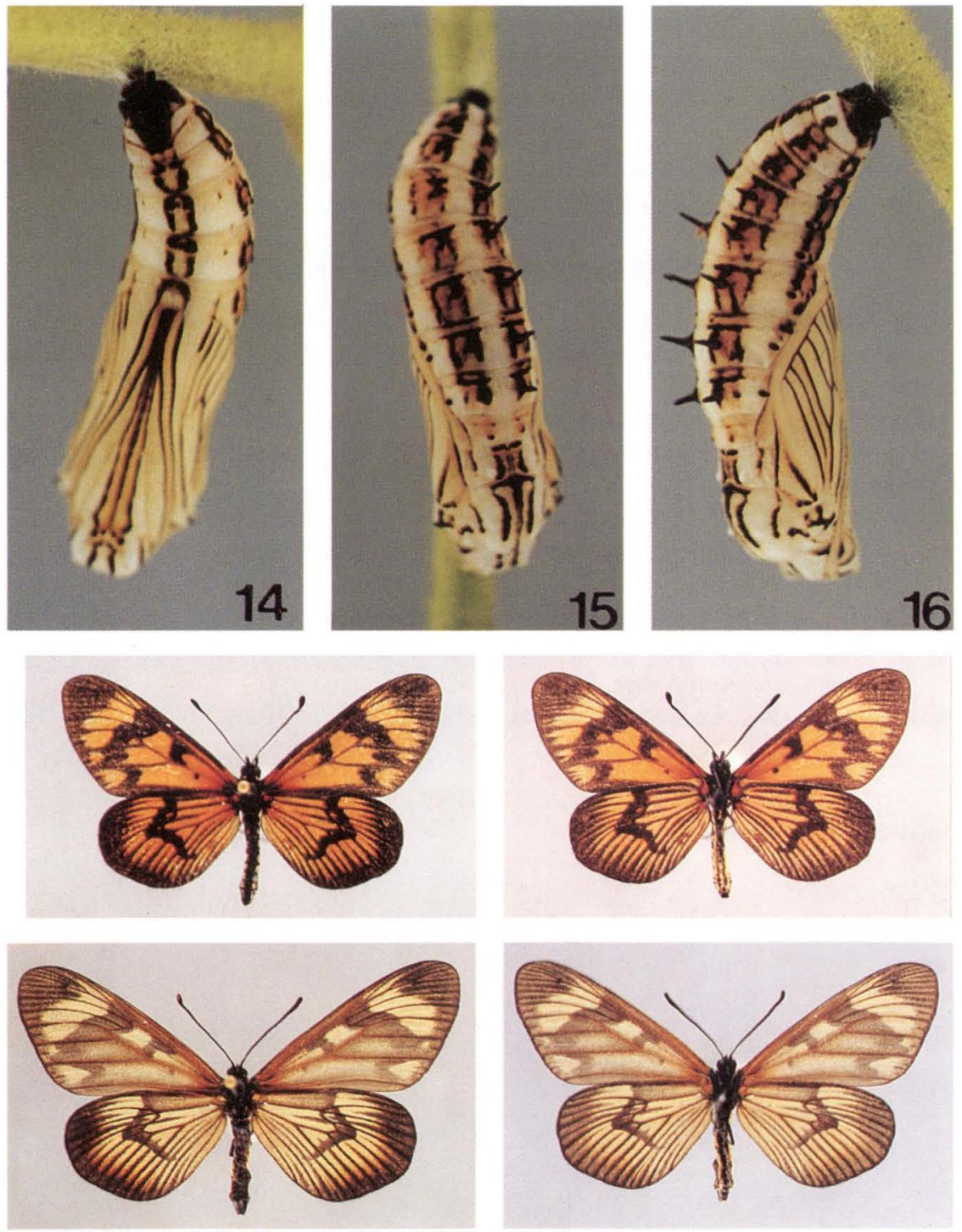

Figs 14-18. Actinote surima. (14-16) Pupa: (14) vista anterior; (15) vista posterior; (16) vista lateral. (17-18) Adulto: (17) macho; (18) fêmea. 


\section{Relações com outros insetos}

Com base em material coletado no campo, foram identificados Pseudochaeta Coquillett, 1895 (Diptera, Tachinidae, Eumasicerini) parasitando larvas e Oplomus catena (Drury, 1782) (Hemiptera, Pentatomidae, Asopinae) predando larvas de terceiro a quinto ínstares. Em laboratório um único exemplar de $O$. catena pode se alimentar de duas a três larvas com 1,3 a 1,5 cm de comprimento a cada dois dias.

AGRADECIMENTOS. À Dra. Jocélia Grazia pela identificação da espécie de Asopinae e ao Dr. Ronaldo Toma pela identificação do gênero de Tachinidae.

\section{REFERÊNCIAS BIBLIOGRÁFICAS}

Biezanko, C.M.; A. Rufinelli \& D. LinK. 1974. Plantas e otras substancias alimenticias de las orugas de los lepidopteros Urugayos. Rev. Centro Ciências Rurais, Santa Maria, 4 (2):107-148.

HINTON, H.E. 1946. On the homology and nomenclature of the setae of lepidopteran larvae, with some notes on the phylogeny of the Lepidoptera. Trans. R. Ent. Soc. Lond. 97: 1-37.

PenZ, C.M. \& R.B. Francini. 1996. New species of Actinote Hübner (Nymphalidae:Acraeinae) from southeastern Brazil. Jour. Lep. Soc. 50 (4): 309-320.

Peterson, A. 1962. Larvae of Insects. An Introduction to Neartic Species. Part I. Lepidoptera and Plant Infesting Hymenoptera. Michigan, Edwards Brothers, Inc. Ann Arbor, 315p.

STEHR, F.W. 1987. Immature Insects. Dubuque, Kendall Hunt, Vol. I, I-XII+754p.

Recebido em 22.II.1998; aceito em 17.XI.1999. 